\title{
COMMUNICABLE DISEASES, NSW: MAY 2001
}

\section{TRENDS}

The onset of autumn brought with it further declines in pertussis and salmonellosis notifications (Figure 1, Table 2). Hepatitis A, rubella and measles have all remained uncommon in recent months. Autumn tends to be the peak season for legionnaires disease, but so far in 2001, no particular peak has emerged in notifications. However, it is timely to remind building owners of the importance of ensuring that cooling towers are regularly inspected and cleaned, to minimise the risk of contamination with legionella bacteria.

\section{ENTEROVIRUS 71}

\section{Valerie Delpech, Lorraine Young, Bill Rawlinson and Dominic Dwyer}

Hand, foot and mouth disease (HFMD) is a childhood disease that causes blisters, often in the mouth and on the hands and feet. It is usually not a serious illness. It can be caused by a number of different types of viruses, and is spread through contact with the fluid of the blisters, saliva and/or respiratory droplets of an infected person. Viruses are also shed in the faeces of affected people, who can remain infectious for several weeks. There is no vaccine against HFMD. Frequent handwashing and attention to personal hygiene may help in the prevention of the disease. HFMD is endemic both in Australia and throughout the world.

While infections with the group of viruses that are associated with HFMD usually cause only mild illness or no symptoms at all, they are rarely associated with neurological complications including meningoencephalitis. There have been recent well-publicised outbreaks of HFMD caused by the virus Enterovirus 71 (EV71). In 1997, there was an outbreak in Sarawak, Indonesia, in which about 34 children were reported to have died. In 1998, there was an outbreak in Taiwan, in which over 100,000 children were reported to be infected with EV71, and 80 were reported to have died. In 1999, a small outbreak of EV71 was reported in Western Australia. ${ }^{1}$

Between November 2000 and February 2001, four infants were admitted to the Intensive Care Unit (ICU) of the Sydney Childrens Hospital (SCH) and two to the ICU at Nepean Hospital. All were diagnosed with enteroviral meningo-encephalitis. Two of the children had a history of HFMD. The two children admitted to the Nepean Hospital recovered and were discharged in February 2000.

Three of the four children at $\mathrm{SCH}$ remain in a critical condition. EV71 was identified in three cases and typing indicates that the organisms are identical. One case remains untyped. However, this EV71 strain is distinguishable from strains isolated during the recent outbreak in Western Australia.

The SCH Emergency Department reported larger than usual number of presentations of HFMD during November and December 2000. Rates have subsequently dropped.

Public health units were placed on alert since late December. Emergency Departments were updated at this time and requested to collect additional specimens from children presenting with suspected viral meningo-encephalitis.

Other enteroviruses can also be associated with HFMD and/or meningencephalitis, and there have been significant numbers of Coxsackie B4 and other enteroviruses isolated and typed at the ICPMR, Westmead Hospital. Current NHMRC recommendations- to exclude cases from childcare facilities until all blisters have driedshould be followed. ${ }^{2}$

\section{References}

1. McMinn P, Stratov I, Nagarajan L and Davis S. Neurological manifestations of Enterovirus 71 infection in children during an outbreak of Hand, foot and mouth disease in Western Australia. Clin Infect Dis 2001: 32.

2. Staying Healthy in Child Care; Preventing Infectious diseases in child care (2nd edition). Department of Health and Family Services.

\section{ARBOVIRUS ACTIVITY}

\section{Richard Russell, Stephen Doggett, Linda Hueston, Dominic Dwyer on behalf of the NSW Arbovirus Surveillance and Mosquito Monitoring Program ICPMR, Westmead Hospital, Westmead}

This month we present a new feature, results of the NSW Arbovirus Surveillance and Mosquito Monitoring Program. The program provides data on mosquito trapping activities from both coastal and inland NSW, as well as data on weekly blood tests from sentinel chickens located in flocks in western NSW. Mosquito trapping is primarily an indicator of local mosquito activity, and thus of possible arbovirus infection (Murray Valley encephalitis virus and Kunjin virus, Ross River virus and Barmah Forest) in humans. The testing of chickens began in 1979 to provide an early warning of flavivirus activity (that is, Murray Valley encephalitis virus and Kunjin virus), and thus the risk to humans posed by these diseases. The variability of local conditions means that interpreting summary statewide data is problematic. In February 2001, for the first time since the commencement of the program, MVE activity was confirmed-in sentinel chickens tested in late January_in the Far Western and Macquarie areas of 


\section{TABLE 1}

RESULTS OF MOSQUITOTRAPPING AND SENTINEL CHICKENTESTING, NSW, NOVEMBER 2000-MARCH 2001

\begin{tabular}{|c|c|c|c|c|c|}
\hline Month & $\begin{array}{l}\text { Mosquito } \\
\text { traps }\end{array}$ & $\begin{array}{l}\text { Mosquitoes } \\
\text { Trapped }\end{array}$ & $\begin{array}{l}\text { Viruses detected } \\
\text { in mosquitoes }\end{array}$ & $\begin{array}{l}\text { Chicken flocks } \\
\text { Tested (no. birds) }\end{array}$ & $\begin{array}{c}\text { Chicken flocks with } \\
\text { flavivirus } \\
\text { seroconversions }\end{array}$ \\
\hline November & 48 & 15845 & 0 & 9 (393) & 0 \\
\hline December & 125 & 73021 & 6 Sindbis & 9 (489) & 0 \\
\hline January & 162 & 28963 & $\begin{array}{l}13 \text { Sindbis } \\
1 \text { Ross River }\end{array}$ & 10 (189) & $\begin{array}{l}2 \text { KUN (2 flocks) } \\
4 \text { MVE (3 flocks) } \\
3 \text { Both (2 flocks) }\end{array}$ \\
\hline February & 173 & 58916 & $\begin{array}{l}5 \text { Sindbis } \\
4 \text { Ross river } \\
2 \text { Kunjin }\end{array}$ & $10(405)$ & $\begin{array}{l}7 \text { KUN (4 flocks) } \\
1 \text { MVE (1 flock) } \\
1 \text { Both (1 flock) }\end{array}$ \\
\hline March & 160 & 24860 & 1 Kokobera & $10(672)$ & $\begin{array}{l}25 \text { KUN (8 flocks) } \\
2 \text { MVE (1 flock) } \\
1 \text { Both ( } 1 \text { flock) }\end{array}$ \\
\hline
\end{tabular}

NSW. Evidence of Kunjin virus was also detected in February Greater Murray Area mosquitoes and chickens.

Kunjin and Murray Valley encephalitis viruses remained active in western NSW in March (Table 1). No human clinical cases of Kunjin or Murray Valley encephalitis cases were reported. Reports of human infections with Ross River virus were most common in the northern coastal areas and south west of the state. Mosquito numbers generally declined across the state through March, although unusually large collections were made at Ballina, following heavy localised rainfall, and from the Port Stephens area. Note that Sindbis and Kokobera viruses are rarely reported as causing human illness.

For complete surveillance results, consult the NSW Arbovirus Surveillance web site at:

www.arbovirus.health.nsw.gov.au. 


\section{FIGURE 1}

\section{REPORTS OF SELECTED COMMUNICABLE DISEASES, NSW, JANUARY 1996TO MARCH 2001, BY MONTH OF ONSET}

These are preliminary data: case counts for recent months may increase because of reporting delays. Laboratory-confirmed cases, except for measles, meningococcal disease and pertussis _ actual __ predicted after adjusting for likely reporting delays

\begin{tabular}{|rc|}
\hline \multicolumn{2}{|c|}{ NSW population } \\
Male & $50 \%$ \\
$<5$ & $7 \%$ \\
$5-24$ & $28 \%$ \\
$25-64$ & $52 \%$ \\
$65+$ & $13 \%$ \\
Rural $^{*}$ & $42 \%$ \\
\hline
\end{tabular}

\begin{tabular}{|rc|}
\hline \multicolumn{2}{|c|}{ Jan-Mar 01} \\
Male & $52 \%$ \\
$<5$ & $<1 \%$ \\
$5-24$ & $10 \%$ \\
$25-64$ & $81 \%$ \\
$65+$ & $9 \%$ \\
Rural & $96 \%$ \\
\hline
\end{tabular}

cases

500

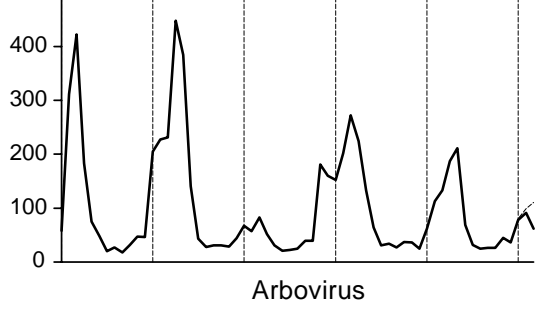

Jan-Mar 01 Male $50 \%$ $<5 \quad 52 \%$ $5-24 \quad 26 \%$ $25-64 \quad 18 \%$ $65+4 \%$ Rural $66 \%$

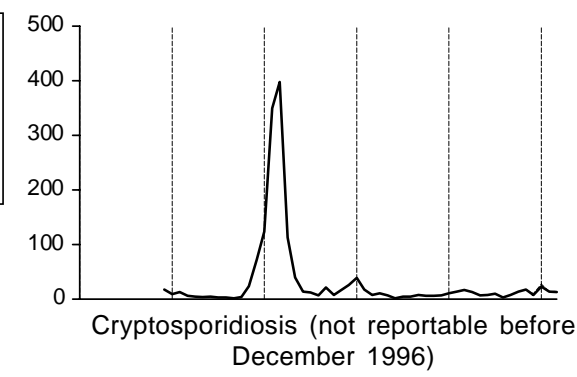

\begin{tabular}{|rc|}
\hline \multicolumn{2}{|c|}{ Jan-Mar 01} \\
Male & $88 \%$ \\
$<5$ & $0 \%$ \\
$5-24$ & $20 \%$ \\
$25-64$ & $80 \%$ \\
$65+$ & $<1 \%$ \\
Rural & $20 \%$ \\
\hline
\end{tabular}
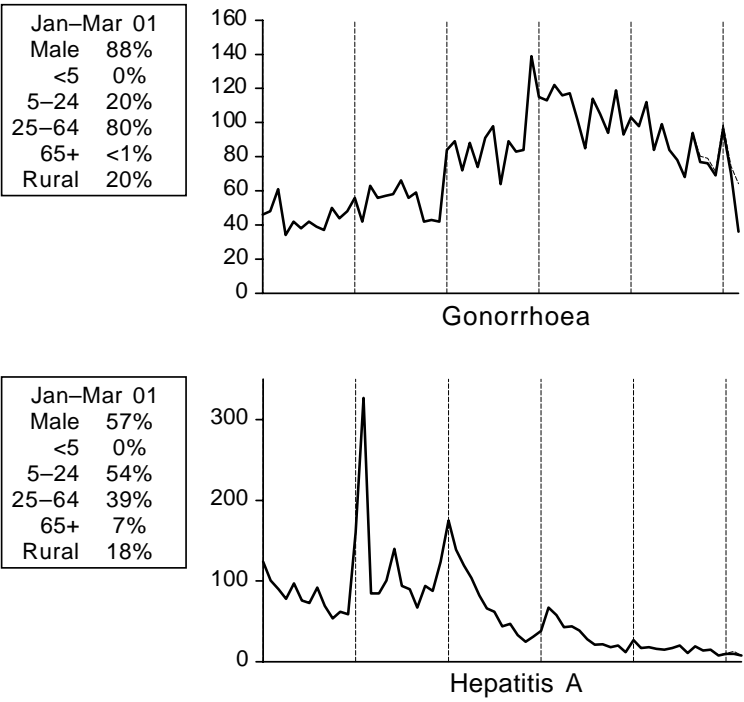

\begin{tabular}{|rc|}
\hline \multicolumn{2}{|c|}{ Jan-Mar 01 } \\
Male & $85 \%$ \\
$<5$ & $1 \%$ \\
$5-24$ & $71 \%$ \\
$25-64$ & $28 \%$ \\
$65+$ & $0 \%$ \\
Rural & $83 \%$ \\
\hline
\end{tabular}

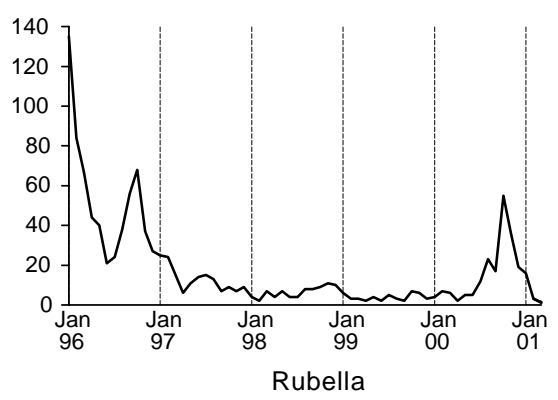

* For definition, see NSW Public Health Bulletin, April 2000

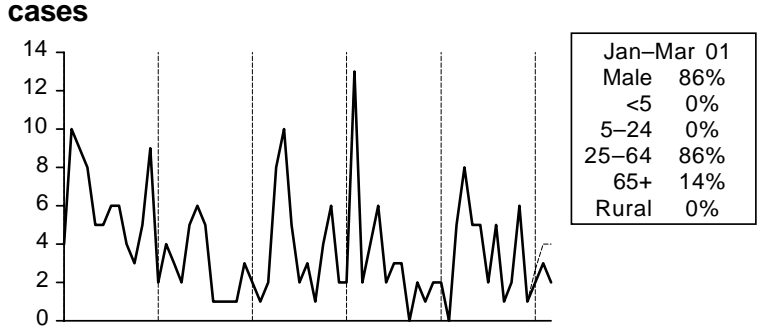

HIV (new diagnoses)

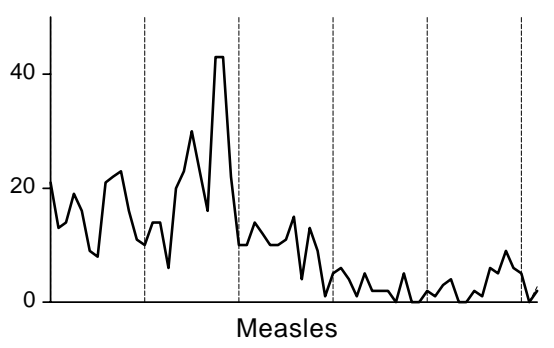

Jan-Mar 01 Male $71 \%$ $<5 \quad 29 \%$ $5-24 \quad 57 \%$ $25-64 \quad 14 \%$ $65+0 \%$ Rural $14 \%$
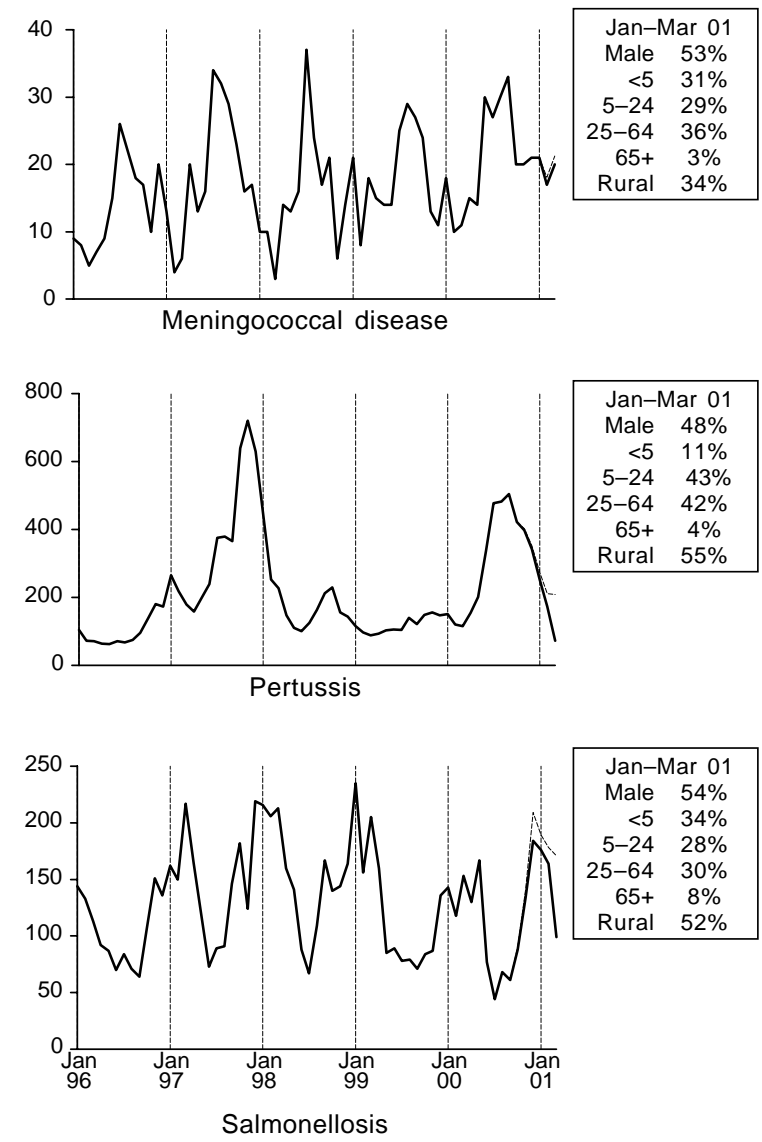
Blood-borne and sexually transmitted

AIDS

HIV infection*

Hepatitis B - acute viral

Hepatitis C - acute

Hepatitis C - other*

Hepatitis D - unspecified ${ }^{*}$

Hepatitis, acute viral (not otherwise specified)

Chancroid
Chlamydia (genital)

Gonorrhoea*

Syphilis

Vector-borne

Arboviral infection (BFV)*

Arboviral infection (RRV)*

Arboviral infection (Other)

\section{Zoonoses}

(anthrax

Brucellosis*

Leptospirosis

Lyssavirus

Respiratory and other

Blood lead leve

Invasive Pneumococcal Infection

Legionnaires' Longbeachae

'Legionnaires' Pneumophila

Legionnaires' (Other)

Leprosy

(invasive)

Mycobacterial tuberculosis

Vaccine-preventable

Adverse event after immunisation

$H$.influenzae $b$ infection (invasive)

Measles

Mumps*

Pertussis

Tetanus

Faecal-oral

Botulism
Cholera*

Cryptosporidiosis*

iardiasis

food borne illness (not otherwise specified)

Gastroenteritis (in an institution)

Hepatitis A

Hepatitis E*

Listeriosis

Salmonellosis (not otherwise specified) ${ }^{\star}$

Typhoid and paratyphoid*
Shigellosis

Verotoxin producing Ecolit

* lab-confirmed cases only

CSA = Central Sydney Area

WSA $=$ Western Sydney Area 